\title{
ĐÁNH GIÁ KẾT QUẢ BÓC NỘI MẠC ĐỘNG MẠCH VÀNH PHỐI HỢP TRONG PHẪU THUẠT BẮC CẦU CHỦ VÀNH
}

\author{
Nguyễn Công Hưu* , Đoàn Quốc Hung**, Nguyễn Hũu Ước**, Lê Ngọc Thành*
}

\section{TÓM TẮT}

Nghiên cứu mô tả, 24 bệnh nhân hẹp 3 thân mạch vành được phẫu thuật bắc cầu phối hợp bóc nội mạc mạch vành trong thời gian từ 2011 2014, thời gian theo dõi trung bình $51,2 \pm 13,7$ tháng. 24 bệnh nhân ( nam: 20 nữ: 4), tuổi trung bình 63, 8 (52 - 81 tuổi), bệnh nhân được bắc tối thiểu 3 cầu nối vào 3 thân mạch vành (số

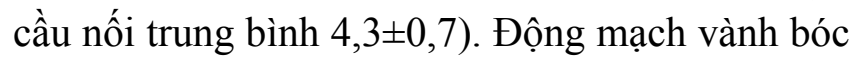
nội mạc: liên thất trước $24,1 \%$, vành phải: $37,9 \%$, động mạch mũ: $13,8 \%$, nhánh chéo: $24,1 \%$. Thời gian chạy máy tim phổi $180,9 \pm 28,2$ phút; cặp động mạch chủ 147,2 $\pm 26,0$ phút; thở máy $18,9 \pm 10,5$ giờ ; nằm hồi sức 4,8 $\pm 0,9$ ngày, tử vong sớm: $2(8,3 \%)$. Không có tai biến về mặt kỹ thuật. Tử vong trong thời gian theo dõi 2 bệnh nhân. Chụp kiểm tra 17 cầu nối: 2 cầu nối tắc, 15 cầu nối thông. Bóc nội mạc mạch vành phối hợp là giải pháp lựa chọn trong phẫu thuật bắc cầu chủ vành nhằm đạt được mục đích tái tưới máu mạch vành toàn bộ. Phẫu thuật được chỉ định hạn chế trong trường hợp thương tổn nặng lan tỏa gây tắc hoàn toàn hoặc gần hoàn toàn, mạch xơ vữa nặng khó thực hiện được miệng nối một cách có chất lượng. Chỉ định được phẫu thuật viên quyết định trong mổ.

\section{SUMMARY}

\section{CORONARY ARTERY ENDARTERECTOMY DURING CORONARY ARTERY BYPASS GRAFTING}

24 patients (20 males, 4 females) with severe coronary disease undergoing $\mathrm{CABG}$ operations with concomitant coronary artery endarterectomy. They were in selected cohort with minimum of three grafts for three main vessles. All patents were operated by the same surgeons. Mean age was 63.8 years. Number of grafts: $4,3 \pm 0.7$ vessels per patient. CE was performed on left anterior descending artery $24,1 \%$, right coronary artery $37,9 \%$, on circumflex artery $13,8 \%$ and diagonal artery $24,1 \%$. Cross-clamp times 147,2 $\pm 26,0$ minutes, perfusion times $180,9 \pm 28,2$ minutes, ventilated time: $18,9 \pm 10,5$ hours, ICU stays: 4,8 $\pm 0,9$ days. Operative mortality: 2 patients $(8.3 \%)$. No technical complication. Follow up: $51,2 \pm 13,7$ months. Mid-term mortality 2 patients(9,52\%). Coronary bypass angiography: graft patency 15, occlusion 2 . Coronary endarterectomy should be considered an acceptable adjunct to $\mathrm{CABG}$ for patients with extensive coronary artery disease to achieve complete revascularization.

\section{I. ĐẶT VẤN ĐỀ}

Bắc cầu chủ vành là phẫu thuật thường quy trong phẫu thuật tim hở điều trị bệnh lý hẹp mạch vành do xơ vữa. Để đạt được việc tái tưới máu toàn bộ trong những trường hợp mạch thương tổn nặng các tác giả trên thế giới đã có nhưng thông báo về việc phối hợp bóc nội mạc động mạch vành khi phẫu thuật bắc cầu chủ vành. Tuy nhiên đây vẫn là vấn đề còn gây nhiều tranh cãi do tính phức tạp và những nguy cơ của phẫu thuật $(1,2)$.Tại Việt Nam cho tới nay chúng tôi chưa thấy tác giả nào đề cập tới kỹ thuật này.Nghiên cứu nhằm mô tả kỹ thuật, tìm hiểu về chỉ định và đánh giá kết quả sau mổ.

\footnotetext{
* Trung tâm tim mạch bệnh viện E

** Bệnh viện Việt Đúcc

Nguời chịu trách nhiệm khoa học: PGS.TS. Đoàn Quốc Hung Ngày nhận bài: 01/08/2017 - Ngày Cho Phép Đăng: 07/08/2017 Phản Biện Khoa học: GS.TS. Bùi Đức Phú PGS.TS. Đặng Ngoc Hùng
} 


\section{II. ĐỐI TƯợng VÀ PHƯớng PHÁP NGHIÊN CỨU}

Nghiên cứu mô tả, được thực hiện trên 24 bệnh nhân thương tổn nặng được phẫu thuật bắc ít nhất 3 cầu nối vào ba thân mạch vành kết hợp bóc nội mạc động mạch vành trong thời gian từ 2011 - 2014 tại trung tâm tim mạch bệnh viện $\mathrm{E}$. Thời gian theo dõi trung bình 51,2 $\pm 13,7$ tháng. Bệnh nhân được phẫu thuật bắc cầu chủ vành theo phương pháp kinh điển với tuần hoàn ngoài cơ thể, cặp động mạch chủ làm ngừng tim. Các thông tin trước, trong và sau mổ được thu thập theo một mẫu thống nhất. Xử lý số liệu theo phương pháp thống kê y học, sử dụng phần mềm SPSS.

\section{KẾT QUẢ NGHIÊN CÚU}

Bảng 3.1.Đặc điểm chung, tiền sử bệnh

\begin{tabular}{|c|c|c|c|c|}
\hline \multicolumn{2}{|l|}{ Đặc điểm } & \multicolumn{2}{|c|}{$\mathrm{n}=\mathbf{2 4}$} & Trung bình \\
\hline \multicolumn{2}{|l|}{ Tuổi (năm) } & & & $63,8 \pm 7.5 \quad(52-81)$ \\
\hline \multicolumn{2}{|l|}{ BMI } & & & $22,7 \pm 2.79(17,6-27,5)$ \\
\hline \multirow[t]{2}{*}{ Giới } & Nam & 20 & $83,3 \%$ & \\
\hline & Nữ & 4 & $16,7 \%$ & \\
\hline \multicolumn{2}{|l|}{ THA } & 17 & $70,1 \%$ & \\
\hline \multicolumn{2}{|l|}{ Tiểu đường } & 6 & $25 \%$ & \\
\hline \multicolumn{2}{|l|}{ Hút thuốc lá } & 11 & $45,8 \%$ & \\
\hline \multicolumn{2}{|l|}{ Suy thận } & 2 & $8,3 \%$ & \\
\hline \multicolumn{2}{|c|}{ Tiền sử NMCT } & 3 & $12,5 \%$ & \\
\hline \multicolumn{2}{|c|}{ Tiền sử đặt Stent } & 4 & $16,7 \%$ & \\
\hline \multicolumn{2}{|l|}{ TBMMN } & 3 & $12,5 \%$ & \\
\hline \multirow[t]{3}{*}{ EURO Score } & $0-2$ & 5 & $20,8 \%$ & $5,1 \pm 3,6$ \\
\hline & $3-5$ & 10 & $41,7 \%$ & \\
\hline & $\geq 6$ & 9 & $37,5 \%$ & \\
\hline
\end{tabular}

Bảng 3.2: Triệu chứng cơ năng trước mổ

\begin{tabular}{|l|l|cc|}
\hline \multicolumn{2}{|c|}{ Triệu chứng cơ năng trước mổ } & \multicolumn{2}{c|}{$\mathrm{n}=24$} \\
\hline \multirow{2}{*}{ NYHA } & I,II & 18 & $75 \%$ \\
\cline { 2 - 4 } & III,IV & 6 & $25 \%$ \\
\hline \multirow{2}{*}{ CCS } & I,II & 15 & $62,5 \%$ \\
\cline { 2 - 4 } & III, IV & 9 & $37,5 \%$ \\
\hline
\end{tabular}


Bảng 3.3: Kết quả phẫu thuật

\begin{tabular}{|c|c|c|c|}
\hline \multicolumn{2}{|l|}{ Kết quả phẫu thuật } & \multicolumn{2}{|l|}{$\mathbf{n}$} \\
\hline \multirow[t]{4}{*}{ Mạch bóc nội mạc } & LAD & 7 & $24,1 \%$ \\
\hline & RCA & 11 & $37,9 \%$ \\
\hline & $\mathrm{Cx}$ & 4 & $13,8 \%$ \\
\hline & Diag & 7 & $24,1 \%$ \\
\hline \multirow[t]{3}{*}{ Mạch ghép } & LIMA & 20 & $83,3 \%$ \\
\hline & RA & 14 & $58,3 \%$ \\
\hline & SV & 24 & $100 \%$ \\
\hline Số cầu nối $(\mathrm{x} \pm \mathrm{SD})$ & \multicolumn{3}{|c|}{$(3-5)$} \\
\hline Thời gian chạy máy tim phổi ( phút) & \multicolumn{3}{|l|}{$180,9 \pm 28,2$} \\
\hline Thời gian cặp ĐMC ( phút) & $147,2 \pm 26,0$ & \multicolumn{2}{|c|}{$(111-209)$} \\
\hline Thời gian hậu phẫu & Sống ra viện (n=22) & \multicolumn{2}{|l|}{ Tử vong(n=2) } \\
\hline Thời gian thở máy( giờ) & $18,9 \pm 10,5 \quad(4-50)$ & \multicolumn{2}{|c|}{$1128 \pm 577(720-1536)$} \\
\hline Thời gian nằm hồi sức( ngày) & $4,8 \pm 0.9$ & \multicolumn{2}{|c|}{$47 \pm 24 \quad(30-64)$} \\
\hline Thời gian nằm viện ( ngày) & $18,9 \pm 10,3 \quad(8-33)$ & \multicolumn{2}{|c|}{$(30-64)$} \\
\hline
\end{tabular}

LAD: động mạch (ĐM) liên thất trước, RCA: ĐM vành phải, Cx: ĐM mũ, Diag: nhánh chéo, LIMA: ĐM ngực trong bên trái, RA: ĐM quay, SV: tĩnh mạch hiển lớn

Bảng 3.4: Tai biến, biến chứng

\begin{tabular}{|l|c|c|}
\hline Tai biến, biến chứng & $\mathbf{n}$ & \% \\
\hline Chảy máu mổ lại & 1 & 4,1 \\
\hline Suy thận phải thẩm phân phúc mạc & 2 & 8,3 \\
\hline Nhiễm trùng huyết & 2 & 8,3 \\
\hline Viêm phổi & 3 & 12,5 \\
\hline Viêm xương ức & 1 & 4,1 \\
\hline Tử vong & 2 & 8,3 \\
\hline
\end{tabular}

Bảng 3.5: Kết quả trung hạn

\begin{tabular}{|c|c|cc|}
\hline \multirow{2}{*}{$\begin{array}{c}\text { Chụp kiểm tra cầu } \\
\text { nối }(\mathrm{n}=17)\end{array}$} & Thông & 15 & $(88,2 \%)$ \\
\cline { 2 - 4 } & Tắc & 2 & $(11,8 \%)$ \\
\hline \multicolumn{2}{|c|}{ Tử vong } & 2 & $(9,52 \%)$ \\
\hline
\end{tabular}

Tổng số 29 mạch được bóc nội mạc, chụp lại kiểm tra 17 cầu nối(58,62\%).

22 bệnh nhân trong thời gian theo dõi, 1 trường hợp tử vong do tai nạn giao thông, 2 bệnh nhân tử vong do bệnh. 


\section{IV.BÀN LUẬN}

Bóc nội mạc động mạch vành phối hợp trong bắc cầu chủ vành nhằm đạt mục tiêu tái tưới máu toàn bộ. Phẫu thuật bóc nội mạc động mạch vành lần đầu tiên được giới thiệu vào năm 1957 bởi Bailey, thực hiện không có tuần hoàn ngoài cơ thể, không kết hợp với phẫu thuật bắc cầu chủ vành. Ông thông báo thành công kỹ thuật cho bệnh nhân nam giới hẹp mạch vành do xơ vữa, có triệu chứng đau thắt ngực không ổn định[3]. Tuy nhiên loại phẫu thuật này đã sớm được thay thế bởi phẫu thuật bắc cầu chủ vành với sự ra đời của máy tuần hoàn ngoài cơ thể. Có nên kết hợp phẫu thuật bóc nội mạc với bắc cầu chủ vành hay không? Những nghiên cứu ban đầu thông báo một tỷ lệ rủi ro cao hơn sau phẫu thuật[2],[4]. Tuy nhiên nhiều nghiên cứu gần đây lại cho thấy kỹ thuật có thể được thực hiện một cách an toàn và cho kết quả khả quan[3],[5]. Tuy vậy cho đến nay vẫn đề vẫn còn gây tranh cãi với những băn khoăn về việc có hay không gia tăng tỷ lệ biến chứng, tử vong và kết quả lâu dài của mạch ghép. Nhiều phẫu thuật viên vẫn còn khá dè dặt trong việc áp dụng kỹ thuật này.

Các nghiên cứu cho thấy thời gian phẫu thuật tương đối dài: nghiên cứu của Schmitto cặp động mạch chủ $119 \pm 31,6$ phút; chạy máy tim phổi $192 \pm 56,5$ phút; thời gian thở máy $52,9 \pm 100,8$ giờ, nằm hồi sức $5,6 \pm 8,4$ ngày ; tử vong bệnh viện $5 \%$; 95\% các bệnh nhân thương tổn 3 thân động mạch vành, số cầu nối trung bình $4 \pm 0,95$ [6]. Damien so sánh giữa hai nhóm bắc cầu đơn thuần và nhóm kết hợp với bóc nội mạc động mạch vành cho kết quả: Thời gian trong phẫu thuật của nhóm có bóc nội mạc dài hơn, tuy nhiên nhóm này thương tổn nhiều mạch hơn (phần lớn bệnh nhân phải sử dụng 3 mạch ghép). Tỉ lệ tử vong, các biến chứng sau mổ khác biệt không có ý nghĩa thống kê (Tử vong: có bóc nội mạc 4\%, bắc cầu đơn thuần $1.3 \%, \mathrm{p}=0.112$ ). Thời gian nằm hồi sức nhóm có bóc nội mạc lâu hơn (75.1 \pm 11.1 vs. $48.6 \pm 2.8$ giờ,p $<0.001)$ tỉ lệ thở máy lâu(16.2\% vs. 8.1\%, p = 0.03)[179].

Trong nghiên cứu này, chúng tôi thực hiện bóc nội mạc động mạch vành phối hợp cho 24 bệnh nhân. Thời gian chạy máy, cặp động mạch chủ và tử vong sau mổ đều có tỷ lệ cao hơn so với kết quả của Damien. Điều này có thể lý giải một phần do đối tượng nghiên cứu của chúng tôi chọn lọc nhóm thương tổn nặng cần phải bắc tối thiểu 3 cầu vào cả 3 thân chính với số lượng cầu nối nhiều hơn so với nghiên cứu của Damien. 2 bệnh nhân tử vong trong nghiên cứu có tình trạng suy thận trước mổ, đau ngực không ổn định với điểm CCS 3, EURO score 4 -6, thời gian hậu phẫu nặng nề: tai biến chảy máu mổ lại cầm máu, viêm xương ức, phải thẩm phân phúc mạc (1bệnh nhân tử vong trong bệnh cảnh nhiễm trùng phổi, xương ức, suy thận; 1 trường hợp tử vong trong bệnh cảnh rối loạn nhịp, suy tim). Mặt khác số lượng bệnh nhân của chúng tôi còn ít hơn, kinh nghiệm cũng như điều kiện chung còn nhiều hạn chế so với các tác giả châu Âu, Mỹ... cũng là điều dễ lý giải cho kết quả trên.

Kết quả sau mổ 2 năm của Damien, tỉ lệ sống còn ở 2 nhóm không có sự khác biệt. Nhồi máu cơ tim ở nhóm bóc nội mạc $73.1 \%$ so với nhóm không bóc nội mạc $71.8 \%(\mathrm{p}=0.05)$. Trong số các bệnh nhân nhồi máu cơ tim ở nhóm bóc nội mạc 27,8\% xảy ra tại vị trí động mạch vành được bóc nội mạc[7]. Schwann với 288 bệnh nhân $\mathrm{BCCV}$ được bóc nội mạc phối hợp, tỉ lệ tử vong năm đầu tiên sau mổ $4,8 \%$; sau 5 năm là $17 \%$. Các bệnh nhân được bóc nội mạc động mạch liên thất trước có tỉ lệ sống còn cao hơn so với nhóm bóc nội mạc động mạch vành phải. Có 68 bệnh nhân phải can thiệp lại trong thời gian theo dõi. Trong số đó 78 cầu nối vào động mạch được bóc nội mạc (38 tĩnh mạch, 24 cầu nối ĐMNT, and 16 động mạch quay); 162 tại cầu nối vào các động 
mạch không được bóc nội mạc(84 cầu nối tĩnh mạch, 40 ĐMNT, 38 động mạch quay). So sánh tỉ lệ cầu nối còn thông ở các động mạch vành bóc và không bóc nội mạc cho thấy không có sự khác biệt với nhóm cầu nối sử dụng mạch ghép động mạch. Trong khi đó các cầu nối tĩnh mạch tắc nhiều hơn ở nhóm có bóc nội mạc: $55 \%$ so với $35 \%(\mathrm{p}=0,05)$ [5]. Kết quả nghiên cứu của chúng tôi sau 51,2 $\pm 13,7$ tháng, tỉ lệ tử vong ở các bệnh nhân có bóc nội mạc $9,52 \%$. Tỉ lệ cầu nối còn thông 88,24\%.

Theo Schmitto, phẫu thuật tim mạch hiện nay đã có nhiều thay đổi, với sự phát triển của khoa học kỹ thuật, các thuốc trong tim mạch, kinh nghiệm của phẫu thuật viên cũng như đội ngũ các thầy thuốc tim mạch - các điều kiện hiện nay không giống như ở thời điểm ban đầu của phương pháp. Vì vậy việc kết hợp bóc nội mạc trong phẫu thuật bắc cầu chủ vành nên được thực hiện khi có chỉ định. Hầu hết các tác giả đều thống nhất chỉ định giới hạn trong những thương tổn nặng, lan tỏa, việc thực hiện miệng nối khó khăn hoặc không thể thực hiện được do xo vữa. Chỉ định được đưa ra trong mổ, dựa trên đánh giá thương tổn của phẫu thuật viên đối với những mạch bị xơ vữa nặng. Trong nghiên cứu của Damien : tất cả mạch được bóc nội mạc đều có thương tổn lan tỏa, tắc hoàn toàn hoặc gần hoàn toàn, đánh giá khó thực hiện được miệng nối, đường kính ngoài tối thiểu $2 \mathrm{~mm}$ và vùng cơ tim trong phạm vi cấp máu của nhánh mạch đó phải còn sống hoặc có khả năng hồi phục sau khi tái tưới máu[7].

\section{V.KẾT LUẬN}

Bóc nội mạc mạch vành phối hợp là giải pháp lựa chọn trong phẫu thuật bắc cầu chủ vành nhằm đạt được mục đích tái tưới máu mạch vành toàn bộ. Tuy nhiên bóc nội mạc cũng có những nguy cơ và kéo dài thời gian mổ, ảnh hưởng đến kết quả phẫu thuật do đó nên được chỉ định hạn chế trong trường hợp thương tổn nặng lan tỏa gây tắc hoàn toàn hoặc gần hoàn toàn, mạch xơ vữa nặng khó thực hiện được miệng nối một cách có chất lượng. Chỉ định được phẫu thuật viên quyết định trong mổ. Lựa chọn phương pháp bóc nội mạc tùy theo kinh nghiệm của phẫu thuật viên.

\section{TÀI LIỆU THAM KHẢO}

1. E. Soylu, L. Harling, H. Ashrafian et al (2014). Does coronary endarterectomy technique affect surgical outcome when combined with coronary artery bypass grafting? Interact Cardiovasc Thorac Surg, 19 (5), 848-855.

2. C. Minale, S. Nikol, M. Zander et al (1989). Controversial aspects of coronary endarterectomy. Ann Thorac Surg, 48 (2), 235-241.

3. S. Kumar, S. Agarwala, C. Talbot et al (2008). Long term survival after coronary endarterectomy in patients undergoing combined coronary and valvular surgery--a fifteen year experience. J Cardiothorac Surg, 3, 15.

4. V.A. Ferraris, J.D. Harrah, D.M. Moritz et al (2000). Long-Term Angiographic Results of Coronary Endarterectomy. Ann Thorac Surg, 69, 1737- 1743.

5. T. A. Schwann, A. Zacharias, C. J. Riordan et al (2007). Survival and graft patency after coronary artery bypass grafting with coronary endarterectomy: role of arterial versus vein conduits. Ann Thorac Surg, 84 (1), 25-31.

6. J. D. Schmitto, P. Kolat, P. Ortmann et al (2009). Early results of coronary artery bypass grafting with coronary endarterectomy for severe coronary artery disease. J Cardiothorac Surg, 4, 52.

7. D. J. LaPar, F. Anvari, J. N. Irvine et al (2011). The impact of coronary artery endarterectomy on outcomes during coronary artery bypass grafting. J Card Surg, 26 (3), 247-253. 